\title{
ASSESSMENT OF WORK ZONE NOISE LEVELS AT A CEMENT FACTORY IN TANGA, TANZANIA
}

MNDEME, F.G. and *MKOMA, S.L.

DOI:http://dx.doi.org/10.4314/ejesm.v5i3.2

Received 24 ${ }^{\text {th }}$ March 2012; accepted $16^{\text {th }}$ April 2012

\begin{abstract}
Noise of machines in cement industries was found to be one of the major occupational hazards for the workers of industrial sector. The objectives of this study were to measure the noise levels in various production sections at a cement factory in Tanga, Tanzania and assess attitudes of workers towards noise health hazards. Noise levels were measured using a digital sound level meter at three appropriate locations of the working zone of the workers. Questionnaires were provided to each worker in selected production section and field under close supervision to avoid influence of one's results by other subject. The results showed maximum noise level at the power plant section with $104.82 \mathrm{dBA}$ and minimum noise level was $50 \mathrm{dBA}$ observed in offices. The maximum and average noise levels measured in most production sections exceeded the allowed limit value of 85 dBA as recommended by Tanzania Bureau of Standards (TBS). Subjective responses indicated that $47.5 \%$ of workers are exposure to noise for more than 5 years whereas, 82.5\% of workers indicated that there could be health effects caused by the noise from machines. The study suggests that, though most workers ever use protective gears during working hours, health checkups for noise related effects should be carried out regularly.

Keywords: Noise levels, Noise exposure, Cement factory, Survey, Tanzania
\end{abstract}

\section{Introduction}

Noise is one of the physical environmental factors affecting human health in today's world. Regulations limiting noise exposure to industrial workers have been instituted in different countries (Eleftheriou, 2002) including Tanzania (TBS, 2005). Noise in work environment is the major cause of concern for safety and health of the factory workers. Industrial laws in Tanzania provide protection to workers from noise pollution as described by the S.140(1) of the Environmental Management Act, 2004 and the National Environmental Standards Committee of the Tanzanian Bureau of Standards (TBS) (TBS, 2005). Exposure duration of $40 \mathrm{hr}$ per week of equivalent noise level of $85 \mathrm{dBA}$ is considered to be safe and noise level above this limit is bound to cause noise induced hearing loss the most common effects among the physiological ones (NIOSHI, 1998; Melamed et al., 2001; Rick, 2004). The general effect of noise on the hearing of

Department of Physical Sciences, Faculty of Science, Sokoine University of Agriculture, P.O. Box 3038, Chuo Kikuu, Morogoro, Tanzania

*Corresponding author emails:stelyusm@gmail.com workers has been a topic of debate among scientists for a number of years (Melnick, 1979; Johnson, 1991; Minja et al., 2003). International Standard Organization (ISO, 1990) has set out comprehensive information on the risk of loss of hearing in relation to age, duration of exposure and the intensity of noise. The psychological effects of noise are more common compared to the physiological ones and they can be seen in the forms of annoyance, stress, concentration disorders and difficulties in resting and perception (Cheung, 2004).

Cement production is one of the major areas that play a role in economy of countries. The studied company in Tanga is among cement factories in Tanzania engaged not only in cement manufacturing but also in cement distribution. The factory has manufacturing facility with output capacity of 80 tones per hour and the product are mainly portland composite cement and cement products catering for construction industry. Knowing the importance of cement factories for the comprehensive development of economy, it is therefore important to assess the work 
conditions for employees with emphasis on noise pollution. Limited studies have been done on the extent of noise exposure to industrial workers and indoor pollution in Tanzania (Minja et al., 2003; Mbuligwe, 2004, Samagwa et al., 2009). Therefore, this study aimed to assess the noise levels in production sections at a cement factory in Tanga region, Tanzania. Attempt was also made to investigate workers attitudes towards noise health effects, in order to suggest appropriate measures to minimize the industrial noise exposure.

\section{Materials and Methods Study area}

The present study was conducted at cement factory $\left(05^{\circ} 7^{\prime} 25^{\prime \prime} \mathrm{S} ; 38^{\circ} 58^{\prime} 23 " \mathrm{E}\right)$ in Tanga city located in North-Eastern coast area of Tanzania. The factory with over 300 employees has manufacturing facility with output capacity of 80 tones per hour and products are mainly portland composite cement and cement products catering to construction industry. The factory also operates in three shifts hours per day for the workers.

\section{Noise level measurements}

The noise levels were measured in August 2011 during working hours between 8.00 am to $4.00 \mathrm{pm}$ for 3 days. Noise measurement was done in various sections of cement processing and non-production sections such as clay crusher, limestone crusher, limestone silo, red soil silo, compressor room, raw mill, preheater, kiln, cement mills, parker, parking plant, garage, workshop, canteen and offices. The offices and restaurant were considered as control sites of the factory environments during the survey. A digital mini sound level meter (IEC 651 Type II) set to the A-weighting scale was used to measure the noise at workers ear level (above the floor). Three appropriate locations of the working zone of the workers were selected for sound pressure level measurement during machines operation. Also the sound level meter was placed at a distance of at least $1.5 \mathrm{~m}$ from the windows.

The following measurements all expressed in $\mathrm{dB}$ were recorded:
1. Maximum sound pressure level (peak noise) - the noise with the maximum intensity $\left(\mathrm{L}_{\max }\right)$ within each 5-minutes period.

2. Minimum sound pressure level (baseline noise) - the noise with the minimum intensity $\left(\mathrm{L}_{\text {min }}\right)$ within each 5-minutes period. All operating sections of the factory were considered for the assessment of worker response on noise pollution.

3. A-weighted equivalent continuous level $\left(\mathrm{L}_{\text {Aeq }}\right)$ (Average) - if one listened to this level of noise constantly for 5 minutes; the ears would be exposed to the same amount of noise as if listened to the varying level of noise recorded in each 5-minutes period.

On the other hand, structured questionnaires were used to assess the workers response on noise pollution in all sections of the factory. The questionnaire was filled by each worker under close supervision to avoid influence of one's results by other subject. Demographic information, nature of work, working hours and experience, noise annoyance and effects, hearing ability, use of protective devices (e.g. earplugs and earmuffs) were among of the questions included on the questionnaire. It should be noted that the questionnaire was also translated into Swahili (national language) to accommodate respondents who do not understand English.

\section{Results and Discussion \\ Noise levels}

Noise levels were measured from different production sections with different types of machines and in non-production sections. Average, minimum and maximum noise levels at different sections in the cement factory are shown in Table 1. The maximum noise level was measured at the power plant which was 104.83 dBA. This value is above the maximum permitted noise level of $85 \mathrm{dBA}$ described by Tanzanian Bureau of Standards (TBS, 2005) and the World Health Organisation (WHO, 1999). The power plant section has power generation which supply electricity to most of the factory processing machines. It was also found that workers in compressor room, raw mill, cement mill, power plant, kiln, clay 
crusher, red soil silo, parker and limestone crusher are exposed to noise levels well above threshold limit of $85 \mathrm{dBA}$. The minimum noise level was $50 \mathrm{dBA}$, measured in the offices. In addition, the results further demonstrated that workers in pre-heater, parking plant, workshop, garage and canteen are less exposed to noise where the average noise values in these sections were below $80 \mathrm{dBA}$.

Table 1 Minimum, maximum and average noise levels at different production section in the cement factory

\begin{tabular}{lccccc}
\hline Production section & \multicolumn{3}{c}{ Noise levels (dBA) } \\
& $\mathrm{L}_{\min }$ & $\mathrm{L}_{\max }$ & $\mathrm{L}_{\text {Aeq }}$ & Std. Dev & Median \\
\hline Clay crusher & 74.20 & 94.72 & 83.82 & 3.45 & 85.05 \\
Limestone crusher & 83.73 & 93.40 & 90.40 & 5.15 & 90.50 \\
Red soil silo & 76.10 & 87.07 & 81.07 & 1.47 & 81.05 \\
Compressor room & 96.67 & 102.02 & 99.48 & 2.68 & 100.65 \\
Raw mill & 92.82 & 96.48 & 93.92 & 2.95 & 93.15 \\
Pre-heater & 74.57 & 77.83 & 75.97 & 0.95 & 75.70 \\
Kiln & 80.53 & 94.10 & 85.18 & 1.85 & 86.00 \\
cement mill & 94.30 & 97.17 & 95.63 & 1.88 & 96.10 \\
Parker & 78.77 & 83.45 & 79.92 & 0.98 & 80.10 \\
Parking plant & 71.83 & 82.83 & 75.70 & 3.00 & 76.50 \\
Workshop & 73.28 & 75.82 & 74.17 & 0.64 & 74.30 \\
Garage & 70.00 & 76.95 & 69.53 & 4.96 & 70.3 \\
Power plant & 103.08 & 104.82 & 104.00 & 2.66 & 103.05 \\
Canteen & 63.23 & 67.75 & 64.77 & 2.42 & 64.50 \\
Offices & 51.80 & 58.08 & 51.50 & 0.57 & 51.50 \\
\hline
\end{tabular}

Figure 1 shows the classification of noise levels (\%) in different factory sections during operation hours. The noise levels were classified into three categories, those below 80 $\mathrm{dBA}$, between 80 and $90 \mathrm{dBA}$, and above 90 dBA. The evaluation of noise were based on limit values and indicated that $40 \%$ of measured sections had noise levels below 80 $\mathrm{dBA}, 28 \%$ were between $80-90 \mathrm{dBA}$ and the remaining $32 \%$ were found to be above 90 dBA. Therefore, on average $60 \%$ of measurements exceeded the allowed limit value of $85 \mathrm{dBA}$ as recommended by Tanzania Bureau of Standard (TBS, 2005). The higher levels were found on especially production sections whereas sections such as in canteen and offices had average noise values were below $80 \mathrm{dBA}$. Only $17 \%$ of the measurements in sections parker, clay crusher and red soil silo had the noise levels below $80 \mathrm{dBA}$ each, while $83 \%$ of measurements for those sections had noise levels between 80-90 dBA. About $50 \%$ of measurements at limestone crusher had noise level between 80-90 dBA and 50\% were above 90dBA. But the highest noise levels were observed at the compressor room, raw mill, cement mill and power plant where by for each section all measurements showed noise levels above $90 \mathrm{dBA}$. 


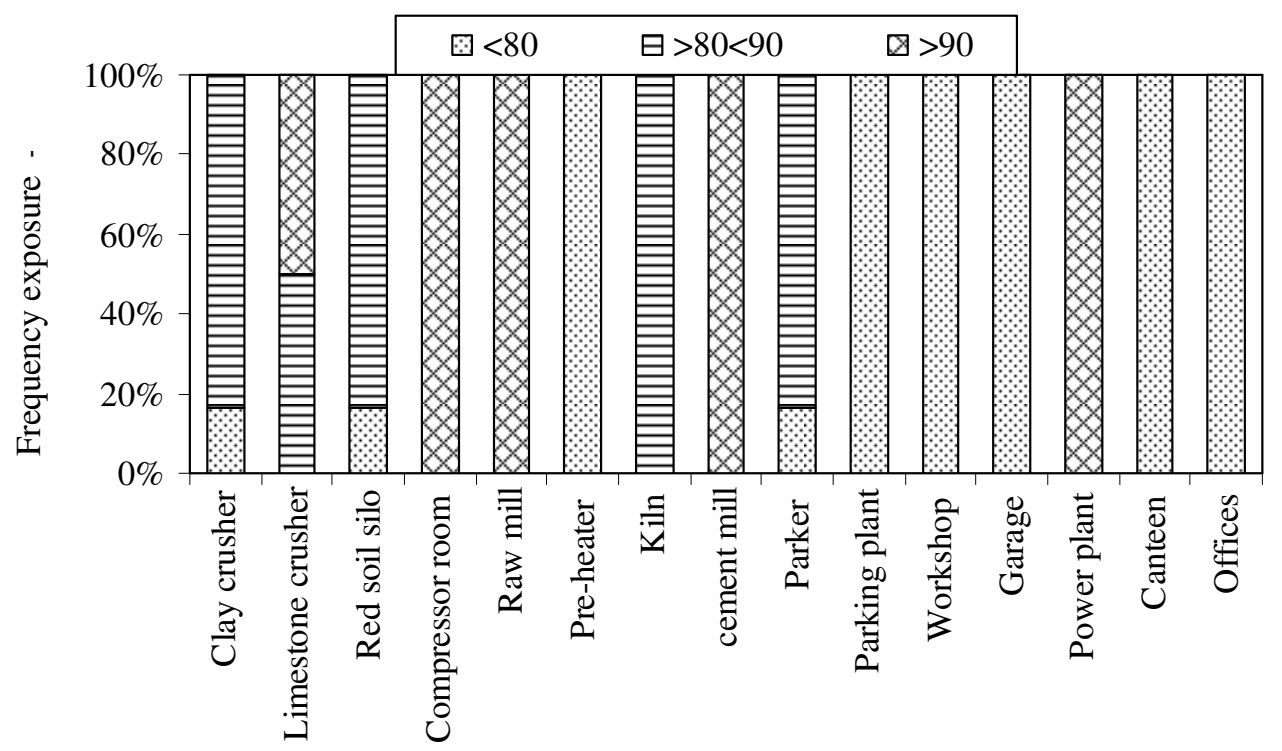

Figure 1 Classification of noise levels in different production sections during operation hours

\section{Workers response to noise pollution}

Table 2 shows the socio-demographic characteristics and frequency distribution of workers at a cement factory. The assessments showed that majority of the interviewed respondents were male making about $92 \%$.
About $48 \%$ of workers were of age ranging between $18-35$ year whereas about $52 \%$ above 35 years. Of the workers, $45 \%$ were secondary schools graduates and $12.5 \%$ college/university graduates. The results also show that the duration of working hours per day was $>5$ hour for all workers.

Table 2 Socio-demographic characteristics and frequency distribution of workers at a cement factory

\begin{tabular}{lcc}
\hline Characteristics & Respondents (n) & Percentage (\%) \\
\hline Sex & 37 & 92.5 \\
$\quad$ Male & 3 & 7.5 \\
$\quad$ Female & 19 & 47.5 \\
Age & 21 & 52.5 \\
$\quad 18-35$ & & \\
$\quad>35$ & 17 & 42.5 \\
Education & 18 & 45.0 \\
$\quad$ Primary & 5 & 12.5 \\
$\quad$ Secondary & 11 & \\
$\quad$ College/University & 10 & 27.5 \\
Duration of exposure (in years) & 19 & 25.0 \\
$\quad<2$ & & 47.5 \\
$2-5$ & 40 & 100 \\
$\quad>5$ & & \\
Duration of working hours per day & & \\
$\quad>5$ hr &
\end{tabular}


Table 3 shows comments among workers at a cement factory on impacts of noise and use of noise protective gears. The results show that around $80 \%$ of respondents were annoyed by noise from factory machines and considered the consequences (health effects related to that matter. However, workers commented that the noises from machines are either high $(50 \%)$ or normal/medium $(50 \%)$. The type of noise health effects that most complained among workers were headache $(20.5 \%)$, hearing problem during conversation $(53.8 \%)$, and irritability (17.9\%). The workers' qualities of hearing for about $98 \%$ of them were almost good except $2 \%$ reported to have hearing quality below average. The hearing capacity of workers over phone was also surveyed where by $50 \%$ reported either hearing without difficulty or miss some conversation. The respondents were asked about the volume of Television (TV) or Radio they prefer to listen; about $75 \%$ said the usually listen in louder volume. It was also reported that only $10 \%$ of the workers require other people to talk louder to them during conversation.

On the other hand, it was found that, most workers $(85 \%)$ know the importance of using protective gears such as earplugs or muffs or canal caps and $70 \%$ use the protective gears while at work. Some of workers $(15 \%)$ did not know the importance of using noise protective gears. The reasons for not using protective gears were mainly dislike and/or being not available in some sections; this may cause lack of concentrations during work. Therefore, these assessments showed that most workers are aware of health effects that can be caused by noise and the importance of using protective gears. Also, even though workers in the factory use protective gears, still there is a risk of health effects due to higher noise levels above TBS limit level of $85 \mathrm{dBA}$ and exposure duration of more than 5 hour per day. This is supported by response from workers who complained of headache and hearing problems than other types of noise health effects.

Table 3 Impact of noise and use of protective gears among workers at a cement factory.

\begin{tabular}{|c|c|c|}
\hline Characteristics & Respondents (n) & Percentage $(\%)$ \\
\hline \multicolumn{3}{|c|}{ Are there health effects caused by noise from machine? } \\
\hline Yes & 33 & 82.5 \\
\hline No & 7 & 17.5 \\
\hline \multicolumn{3}{|l|}{ Comment on the noise from machines } \\
\hline Very high/high & 20 & 50 \\
\hline Normal or medium & 20 & 50 \\
\hline \multicolumn{3}{|l|}{ Types of noise health effects } \\
\hline Headache & 8 & 20.5 \\
\hline Hearing problem (Conversation disruption) & 22 & 53.8 \\
\hline Bad temper/irritability & 7 & 17.9 \\
\hline Difficult to concentrate & 3 & 7.7 \\
\hline \multicolumn{3}{|l|}{ Quality of hearing } \\
\hline Good/Above average & 24 & 60 \\
\hline Average & 15 & 37.5 \\
\hline Below average & 1 & 2.5 \\
\hline \multicolumn{3}{|l|}{ Hearing over phone } \\
\hline Without difficulty & 20 & 50 \\
\hline Do miss some/a lot conversation & 20 & 50 \\
\hline \multicolumn{3}{|l|}{ Sound of TV/Radio } \\
\hline Usually louder & 30 & 75 \\
\hline Usually same loudness/little softer & 10 & 25 \\
\hline
\end{tabular}




\begin{tabular}{|l|c|c|}
\hline Characteristics & Respondents (n) & Percentage (\%) \\
\hline Yes & 4 & 10 \\
\hline No/ Not all of the time & 36 & 90 \\
\hline Ever use earplugs or muffs or canal caps? & 28 & 70 \\
\hline Yes & 12 & 30 \\
\hline No/ Not often & 34 & 85 \\
\hline Is it important to use the protective gears? & 6 & 15 \\
\hline Yes & \multicolumn{2}{|l|}{} \\
\hline No/do not help & 22 & 55 \\
\hline Reason for not using protective gears & 18 & 45 \\
\hline Not available/dislike & & \\
\hline Cause luck of concentration
\end{tabular}

\section{Comparison with other studies}

The results from the present study at a cement factory on noise levels and workers response to impacts of noise in work place are comparable to those reported in other studies (Melamed et al., 2001; Minja et al., 2003; Boateng, and Amedofu, 2004; Mbuligwe, 2004; Rick, 2004). Previous studies carried out by researchers in other factories in Tanzania confirmed increasing prevalence of high noise levels in the workplaces of various factories. Mbuligwe (2004) conducted studies in wood and metal works industries in Dar es Salaam to determining levels and factors that influence noise pollution in small-scale industries and reported higher noise levels than $85 \mathrm{dBA}$, permissible exposure level limit for occupational noise. Another study by Minja et al., (2003) was conducted in two industries at random selection also in Dar es Salaam to determine whether the sound pressure levels in the study areas had sufficient intensity to cause hearing loss. The results showed that noise levels in both studied areas were above the safe limit of $85 \mathrm{dBA}$ as recommended by Tanzania Bureau of Standards. Some workers had noise induced hearing loss and knew that noise causes hearing loss and could be prevented using ear protection gears.

In Kumasi metropolis, Ghana, Boateng and Amedofu (2004) conducted a survey on noise levels in saw mills, corn mills and printing houses so as to determine the impacts of noise levels on hearing capabilities of workers in such working settings. The results showed that noise level in corn mills exceed the limiting value of $85 \mathrm{dBA}$ as recommended by World Health Organization (WHO, 1999). It was also found that $23 \%, 20 \%$ and $7.9 \%$ of workers in corn mills, saw mills and the printing industry have evidence of noise induced hearing loss which were well correlation with noise exposure level and duration of exposure.

Therefore, these studies show that noise, modifies social behaviours, and causes interferes to task performance and annoyance to workers. Studies of occupational and environmental noise exposure also suggest an association of noise exposure with physiological effect like blood pressure. This is supported by the study of Stansfeld and Mark (2003) who investigated the non-auditory effects of noise on health and concluded that the effects of environmental noise on health is strongest for annoyance, sleep and cognitive performance.

\section{Conclusion}

The purpose of this study was to survey noise levels in cement factory and to determine the impact of noise on workers. Our data has shown that there is noise pollution problem in cement factory which can interferes to workers performance. The measured noise levels were found to be higher than TBS and WHO acceptable limit in some production sections. Workers exposed to noise above $85 \mathrm{dBA}$ will eventually develop hearing loss and workers are aware of this hazard. This suggests that specific intervention is required to protect workers exposure to noise health effects at work place. It has also been observed that most workers know the importance of using 
protective gears while at work. However, few workers do not know the importance of using protective gears by assuming that they do not help or they may cause them to lose concentration on their work. The study recommends that workers in noisy production sections of the factory be subject to hearing tests and other related illnesses periodically each year. Also, there is a need to educate (regular training to) those exposed on how best to protect themselves from noise hazards and continue providing them with suitable protective accessories (gears). Considering the important role that hearing plays in our lives, it becomes necessary for the factory authority to protect those at risk from noise health hazards. This is necessarily so, especially in important companies on the country economy such as cement factories.

\section{Acknowledgment}

We acknowledge the financial support from Tanzania Higher Education Students' Loans Board (HESLB) and Sokoine University of Agriculture for granting special research fund to the first author. The authors express sincere thanks to cement factory authority for help in logistics and permission to conduct noise measurements. We are also gratefully to the cooperation and helping hands of the workers who willingly took part in this study.

\section{References}

Boateng, C.A. and Amedofu, G.K. (2004). Industrial noise pollution on the hearing capabilities of workers: a study from saw mills, printing press and corn mills. African Journal of Health Sciences, 11, 55-60.

Cheung, C.K. (2004). Organizational influence on working people's occupational noise protection in Hong Kong. Journal of Safety Research, 35(4), 465-475.

Eleftheriou, P.C. (2002). Industrial noise and its effects on human hearing. Applied Acoustics, 63, 5-42.

ISO-1999, (1990). Acoustics-determination of noise exposure in work place and evaluation of the auditory damage due to noise.

Johnson, D. (1991). Field studies: industrial exposure. Journal of the Acoustical Society of America, 90(1), 170-174.
Mbuligwe, E.S. (2004). Levels and influencing factors of noise pollution from small-scale industries in developing countries. Environmental Management, 33(6), 830-839.

Melamed, S., Fried, Y. and Froom, P. (2001). The interactive effect of chronic exposure to noise and job complexity on changes in blood pressure and job satisfaction: A longitudinal study of industrial employees. Journal of Occupational Health Psychology, 6, 182-195.

Melnick, W.(1979). Hearing loss from noise exposure, Handbook of Noise Control, Harris, C. M (Ed.). Mc. Grow Hill, New York, 15, 1.

Minja, B.M., Moshi, N.H. and Riwa, P. (2003). Noise indused hearing loss among industrial workers in Dar es Salaam. East African Medical Journal, 80(6), 298-302.

National Institute for Occupational Safety and Health, NIOSH, (1998). Criteria for a recommended standard: Occupational noise exposure. Revised Criteria 1998. U.S. Department of Health and Human Services, Center for Disease Control and Prevention, Cincinnati, Ohio, USA.

Rick, N. (2004). Noise exposure standards around the world [monograph on the internet]. Washington: Department of Environmental and Occupational Health Sciences, University of Washington.

Samagwa, D., Mkoma, S.L. and Tungaraza, C.T. (2009). Investigation of Noise Pollution in Restaurants in Morogoro Municipality, Tanzania, East Africa. Journal of Applied Sciences and Environmental Management, 13(4), 29-33.

Stansfeld, S.A. and Matheson, M.P. (2003). Noise pollution: non-auditory effects on health. British Medical Bulletin, 68(1), 243257.

Tanzania Bureau of Standards, TBS, (2005). National Environmental Standards

Compendium EMDC 6(1733). P2: ACOUSTICS - General Tolerance Limits for Environmental Noise, pp.74.

World Health Organization, WHO, (1999).

Guidelines for Community Noise, edited by Birgitta Berglund, Thomas Lindvall, Dietrich H Schwela. Geneva. 